\title{
The Impact of Current Cost Information on Investment Decisions: An Empirical
}

\section{Assessment}

\author{
FARA ElikaI* \\ SHANE MORIARITY** \\ FranCES L. AYRES***
}

Considerable attention has been paid in the accounting literature to the relative merits of reporting current cost net income as compared to historical cost net income. A large number of surveys have found that users want current value information and believe it to be useful (Casey and Sandretto [3], Estes [4], and Louis Harris [6]). In addition, accounting scholars have argued for decades that current value information is useful for decision making. For example, Sterling [16], in a wheat-trading environment, argued that current values are needed for decisions.

Although the demand for current value information seems clear, it is not clear that formal financial statements based on current values are any more useful than historical-cost-based financial statements. Most empirical studies of the information content of current cost disclosures have reported that after controlling for historical cost earnings, current cost disclosures are not relevant. ${ }^{1}$ From an analytic perspective, Ijiri and Noel [8] argue that because current costs are subject to higher variability than historical costs, a current cost income measure is less reliable than a historical cost income measure. As a result, they conclude that current cost income may be less useful for decision making than historical cost income.

To help resolve the question regarding the merits of current value financial statements we undertook a study to gather empirical evidence on the quality of decisions made under alternative reporting systems. Specifically, the study used an experimental approach to determine whether current value disclosures improved investment decisions and whether current cost

*Associate Professor of Accounting, University of North Carolina-Wilmington

**Professor of Accounting. The University of Oklahoma

***Associate Professor of Accounting. The University of Oklahoma

Frances L. Ayres would like to acknowledge the financial support of the KPMG Peat Marwick Foundation and the University of Oklahoma College of Business Noble Foundation.

1. Exceptions are Bildersee and Ronen [13] and Bublitz et al. [2]. Both of these studies reported that FAS No. 33 provided information to the market. 
income is more useful if it is dichotomized into trading (realized) and holding (unrealized) components.

The remainder of this paper is divided as follows: The following section discusses previous research on the topic. This is followed by a discussion of our experimental task and a description of the hypotheses tested. Next the results are discussed. The final section provides conclusions and identifies some limitations in the study.

\section{Previous Research}

Most studies of the usefulness of current cost information have used stock market reactions as an indicator of the information content of current value disclosures. Numerous studies have attempted to determine the impact on stock prices from both the replacement cost disclosures mandated by the Securities and Exchange Commission's (SEC's) Accounting Series Release No. 190 [15], and the requirements of the Financial Accounting Standards Board (FASB) Statement No. 33 [5]. However, attempts to find empirical support for the incremental value of current value information have been mixed (see, for example, Beaver, Griffin, and Landsman [1], Matolcsy [9], McDonald and Morris [10], Murdock [12], and Schaefer [14]). Although most studies report that current value disclosures do not provide incremental information over historical cost disclosures, there is some evidence that they do.

Bildersee and Ronen [13] used a different and more powerful design than prior studies and found that the mandated Statement of Financial Accounting Standards Number 33 (SFAS No. 33) disclosures were informative. Specifically, they find that security returns are positively associated with current cost productive activity growth. Further their results suggest that SFAS No. 33 disclosures provide information on real productive activity that is not available through historical cost financial statements. Bublitz et al. [2] reported that SFAS 33 data provided information in addition to historical cost in aggregate. However, they found that the coefficients associated with particular disclosures were not stable.

The information content studies for current cost disclosures suffer from several common weaknesses that make it difficult to interpret their results. These weaknesses include (1) possible measurement error in the current value disclosures as mandated by Accounting Series Release Number 190 (ASR No. 190) and FASB 33, (2) difficulty in assessing the timing of possible responses to the disclosures, (3) the possible failure of investors to use the information due to a lack of understanding of the data, and (4) the possibility that the market could make estimates of current values from other publicly available sources, thus making the disclosures redundant. 
Hence, although these studies suggest that ASR No. 190 and SFAS No. 33 did not appear to lead to improved disclosures, they do not tell us whether investors find current value information, properly specified, useful in making decisions.

Experimental studies of the impact of current value disclosures have been more limited, but they have also generally failed to support the hypothesis that current value disclosures provide useful information (see McEnroe and Nikolai [11] for a review). However, these studies typically fail to provide an objective criterion for the quality of a decision. Furthermore, they are frequently limited to the use of student subjects.

\section{Experimental Design}

Our experiment was designed to overcome these limitations. First, by using investment professionals as subjects, the external validity of the experiment is increased. Second, we sought a situation where a direct linkage could be observed between the operating decisions of management and the relative attractiveness of the firm as an investment. We concluded that we must use an industry in which the assets acquired have a definite, reasonably short life. In such an environment, we are able to constantly monitor the current values of assets over their entire lives. This, in turn, allows us to unambiguously define correct buy, sell, and hold decisions for the assets. One industry that meets this requirement consists of firms that trade in commodity futures contracts. These contracts have a definite life of usually one year or less. Further, detailed price information is available.

Another advantage of the commodities futures industry is that commodity futures are volatile, generating holding gains and losses over a short period of time. These lead to substantially different income figures for current value than for historical cost financial statements. Furthermore, the public availability of information on commodity futures suggests that investors believe that current value information is useful for decisions. Because our goal was to determine whether or not current value financial statements lead to improved decisions, it seemed logical to select an industry where a known demand for current value information exists.

Historical cost financial statements provide information on gains and losses only when they are realized through sale of the assets. In contrast, current value statements disclose both realized and unrealized gains and losses. Thus, the current value statements provide a more timely signal to investors about changes in the value of a firm's assets, which should allow investors to more accurately assess the relative attractiveness of the firm as an investment prospect. The research design used in this study provides a direct test of whether this is the case. 


\subsection{The Instrument}

We developed a set of four hypothetical firms dealing in commodity futures contracts. The firms traded an identical commodity portfolio consisting of cattle, hogs, wheat, and soybeans. These commodities were chosen because they are actively traded and data are readily available. There were 144 trading decisions for each commodity over a four-year interval. The firms always held three contracts of a commodity (either long or short), with different maturity dates. All firms were endowed with the same amount of initial capital $(\$ 55,000)$ and faced the same number of potential trades. The only difference between the firms was their percentage of correct buy, sell, and hold decisions. A correct decision was one leading to the highest return on a particular contract. The prices of the contracts were obtained from the Chicago Mercantile Exchange (CME) and the Wall Street Journal. The daily opening prices of the contracts were used in the study. The transactions were generated in conformity with $\mathrm{CME}$ trading regulations. That is, the assigned margin deposits were used on both the long and short positions. In the commodity market, contracts for each commodity are traded in a uniform quantity. For the commodities used in this study the contracts are for 40,000 pounds of cattle, 30,000 pounds of hogs, and 5,000 bushels each for wheat and soybeans. Each transaction in the study was for one standard unit. For example, if June cattle were selling at $\$ 0.66 / \mathrm{lb}$, one contract would be $40,000 \times \$ 0.66=\$ 26,400$. The broker's commission and the interest on the cash account were ignored because the net effect is nominal.

For each contract traded, the firms were restricted to holding one contract long or short. Trades were contemplated in the middle of each month. For each contract, we determined the correct strategy for the month. For example, if the firm held a long position in a contract, it could either continue to hold it or sell. By looking ahead at the market data we could easily determine the correct decision. The percentage of correct decisions, in turn, provides an ordering for the attractiveness of the firms as investments. Importantly, this ordering is based on operating decisions and is independent of any accounting measurements or procedures. Furthermore, although in the long run, firms with the most correct decisions will be shown to be the most profitable under any accounting method, the period-by-period variations ensure that no perfect ex ante ranking is possible.

The hypothetical firms made correct decisions an average of 85 percent, 80 percent, 75 percent, and 70 percent of the time over the four year period. ${ }^{2}$

2. The percentages were selected judgmentally. The goal was to have each firm be profitable, but not consistently so. 
Table 1 presents the quarter-by-quarter percentages of the correct decisions for the four firms. Then for each hypothetical firm the predetermined percentages of correct and incorrect decisions were randomly assigned to individual transactions. For each firm there were a total of $\mathbf{5 7 6}$ decisions over the four-year period (four commodities $\times$ three contracts $\times$ twelve months $\times$ four years). ${ }^{3}$

Using data generated from these hypothetical firms, we examined the impact of three forms of financial statements on the quality of investment decisions. Three sets of quarterly financial statements (an income statement and balance sheet prepared at month end) spanning the four years were prepared for each firm. The first set was based on historical costs, the second used current cost, but reported current cost income only in total. The third set also used current cost accounting but reported the components (unrealized holding gains [losses] and trading gains [losses]). ${ }^{4}$

The comparison of the three reporting modes allows us to compare the usefulness of current cost and historical cost information. In addition, we were able to examine whether the components of current cost income provided incremental information over the total. Figure 1 presents a simple numerical example contrasting the three approaches we examine. ${ }^{5}$

There were three different experimental packets corresponding to the three types of financial statements. Each packet contained the appropriate type of financial statement for each of the four firms. An example of one of the financial statements is given in Figure 2. In addition, the packets contained a cover letter, instructions, and a short questionnaire. The cover letter briefly commented on the objective of the project and the instructions provided a short description of the firms and the financial statements. Subjects received only one form of the financial statements (a between-subjects design). There were six questions in the questionnaire. The first question was the primary question in terms of the current study; it asked the respondents to rank the firms in order of their attractiveness as an investment. Questions 2 through 5 were the distractors that asked subjects about the usefulness of various formats for presenting financial data.

3. Although there is no assurance that, case by case, maximizing the number of correct decisions will maximize earnings-we expect that on average this would be the case, and the results bear this out.

4. Holding gains represent unrealized gains (losses) accruing from the beginning of the period until the end of the period for assets not sold. Trading gains (losses) represent realized profits earned from the beginning of the period until the date of sale.

5. There are two common types of current cost based financial statements advocated in the literature-exit value and replacement cost (or entry value). But for commodity contracts, replacement cost is identical to exit value. Thus, our firms' profits are determined solely by the difference between acquisition and disposal prices of contracts. 


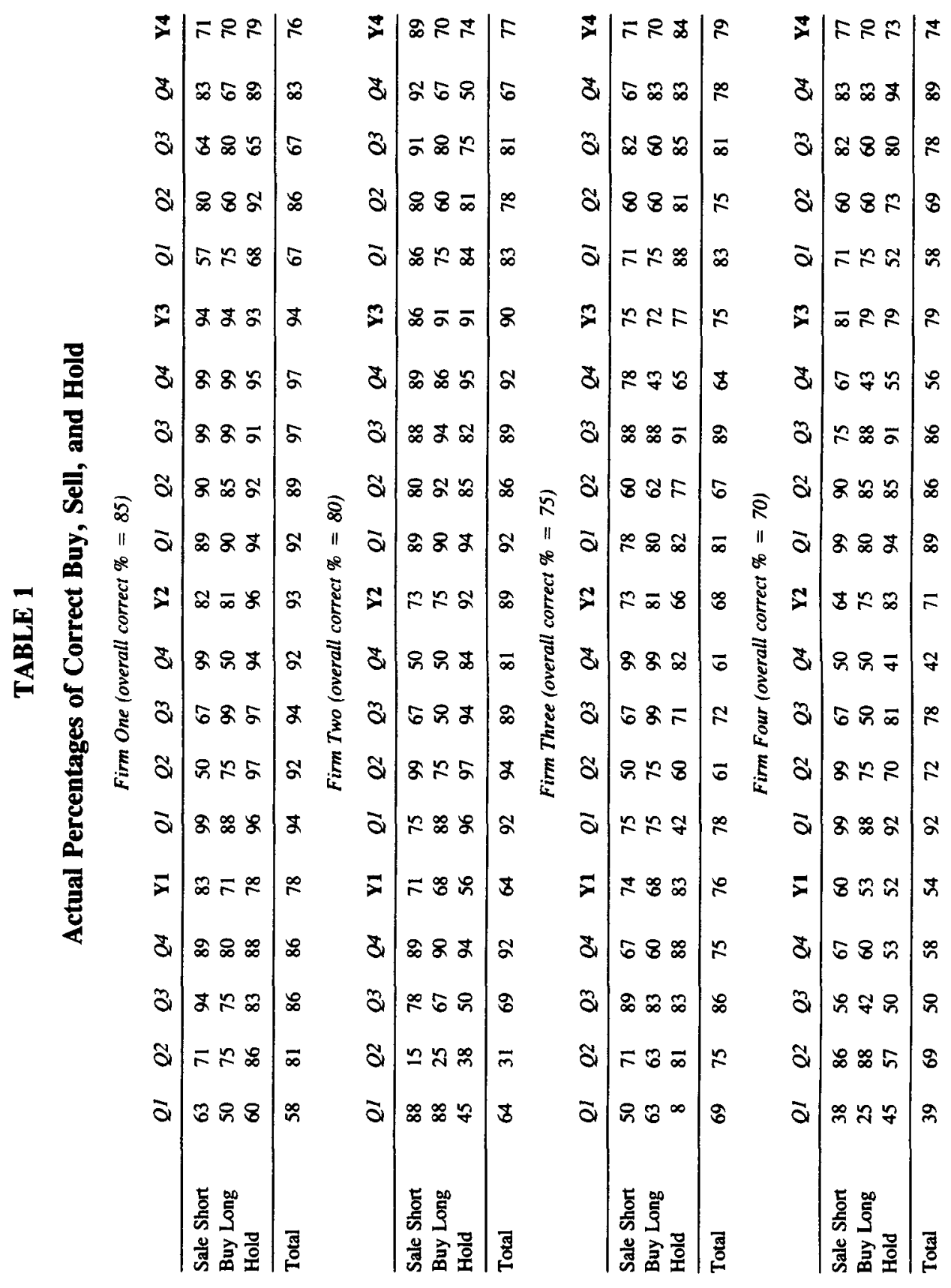




\section{FIGURE 1}

\section{A Numerical Example Contrasting the Three Reporting Methods}

Facts: A trading firm purchases asset $A$ for $\$ 10$ and asset $B$ for $\$ 12$ in period one. At the end of period one, the replacement costs of the assets are A: $\$ 15$, and B: $\$ 20$. During period two, asset $A$ is sold for $\$ 18$. The current value of asset $B$ at the end of the period is $\$ 24$.

\begin{tabular}{lccccr} 
& \multicolumn{2}{c}{ Period 1 } & & \multicolumn{2}{c}{ Period 2 } \\
\cline { 2 - 3 } \cline { 5 - 6 } \multicolumn{1}{c}{ Reporting Method } & Net & Total & & Net & Total \\
Income & Assets & & & Income & Assets \\
\hline Historical Cost & $\$ 0$ & $\$ 22$ & & $\$ 8^{3}$ & $\$ 12$ \\
Total Current Cost & $13^{1}$ & $35^{2}$ & & $7^{6}$ & 24 \\
Component Current Cost & & 35 & & $3^{4}$ & 24 \\
Trading Gains & 0 & - & $4^{5}$ & - \\
Holding Gains & 13 & & &
\end{tabular}

$'(15+20)-(10+12)=13$ total holding gain

${ }^{2} 15+20=35$ current replacement cost

${ }^{3} 18-10=8$ trading gain (historical cost)

${ }^{4} 18-15=3$ trading gain (current cost)

$s^{5} 24-20=4$ holding gain (current cost)

${ }^{6} 3+4=7$ total current cost net income

\subsection{Participants}

The subjects for the study were 105 professionals representing public accounting, internal auditing, bank loan officers, bank investment officers, financial managers, and investment brokers located in the Southwest United States. The participants in the study all had four or more years of college education. On average, they had six years of experience and spent over 40 percent of their time reading, preparing, or evaluating financial statements.

\subsection{Administration of the Experiment}

Each participant was given a packet containing one of the three versions of the financial statements. The version given was randomly determined. The packets were distributed by the participant's supervisor who asked the participant to work alone. The subjects were instructed to compare the four firms in the packet by analyzing the financial data provided for each of them. They were instructed to rank the firms in descending order from the firm that they considered to represent the best alternative as an investment to that which was the least attractive. The review of the four firms and the completion of the questionnaire, on the average, took 20 minutes. 


\section{FIGURE 2}

\section{Example Financial Statement}

Condensed Comparative Financial Data (Current Cost Basis*)

\begin{tabular}{cccc}
\multicolumn{5}{c}{ Year } \\
\hline 1 & 2 & 3 & 4
\end{tabular}

\begin{tabular}{|c|c|c|c|c|}
\hline Investment Income (Loss) & $\$ 118,028$ & $\$ 85,966$ & $\$ 96,810$ & $\$ 122,175$ \\
\hline \multicolumn{5}{|l|}{ Assets } \\
\hline Cash & $\$ 97,615$ & $\$ 191,620$ & $\$ 296,464$ & $\$ 388,330$ \\
\hline Receivables & 149,420 & 104,888 & 10,320 & 195,740 \\
\hline Short-term investments & 88,038 & 137,106 & 207,500 & 113,015 \\
\hline Total & $\$ 335,073$ & $\$ 433,614$ & $\$ 514,284$ & $\$ 697,085$ \\
\hline \multicolumn{5}{|l|}{ Equities } \\
\hline Current liabilities & $\$ 162,045$ & $\$ 174,620$ & $\$ 158,480$ & $\$ 219,106$ \\
\hline Partnership equity & 173,028 & 258,994 & 355,804 & 477,979 \\
\hline Total & $\$ 335,073$ & $\$ 433,614$ & $\$ 514,284$ & $\$ 697,085$ \\
\hline
\end{tabular}

*Assets and liabilities are carried at their current market values. The investment income recognized each period includes both realized gains and changes in the carrying value of assets.

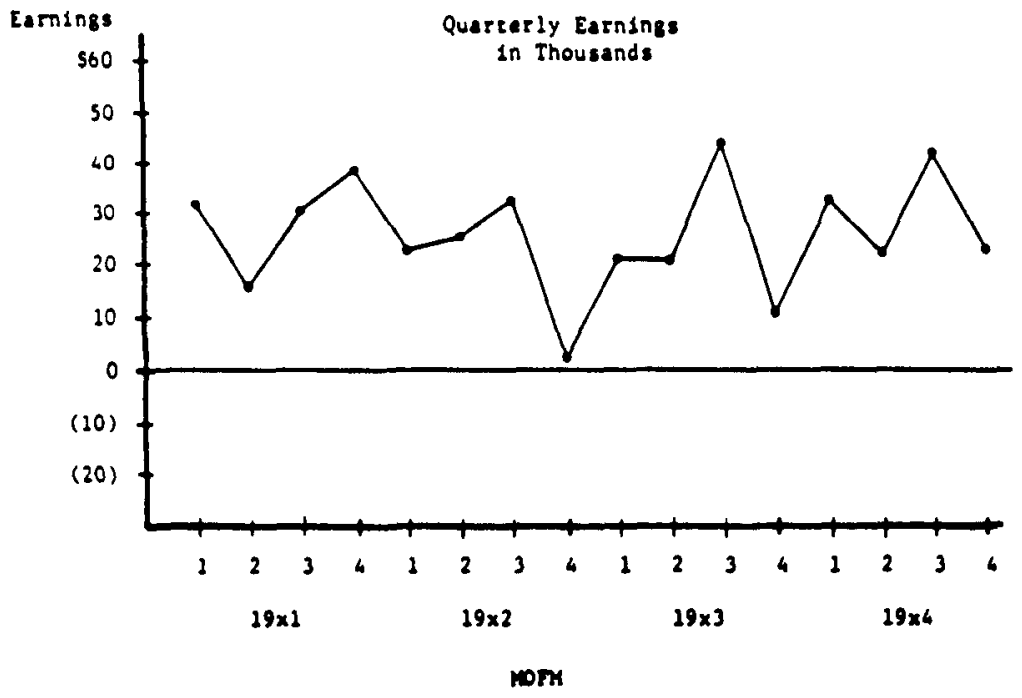

Condensed Comparative Quarterly Earnings

\begin{tabular}{lrrrrr} 
Period & $\begin{array}{c}\text { First } \\
\text { Quarter }\end{array}$ & $\begin{array}{c}\text { Second } \\
\text { Quarter }\end{array}$ & $\begin{array}{c}\text { Third } \\
\text { Quarter }\end{array}$ & $\begin{array}{l}\text { Fourth } \\
\text { Quarter }\end{array}$ & \multicolumn{1}{c}{ Total } \\
\hline Year 1 & $\$ 32,300$ & $\$ 16,150$ & $\$ 30,725$ & $\$ 38,853$ & $\$ 118,028$ \\
Year 2 & 23,960 & 25,155 & 33,095 & 3,756 & 85,966 \\
Year 3 & 20,777 & 20,320 & 44,643 & 11,070 & 96,810 \\
Year 4 & 33,345 & 22,480 & 42,870 & 23,480 & 122,175
\end{tabular}




\subsection{Hypotheses}

Using data obtained from the responses to the experiment, the following hypotheses were tested (expressed in their alternative form):

$H 1$ : Users are able to rank firms more accurately when provided with total current cost (TCC) statements than when provided with historical cost (HC) statements.

H2: Users are able to rank firms more accurately when provided with component current cost $(\mathrm{CCC})$ statements than when given $\mathrm{HC}$ statements.

H3: Users are able to rank firms more accurately when provided with CCC statements than when provided with TCC statements.

These hypotheses imply an increasing level of information provided by financial statements formed using historical cost, total current cost, and component current cost information.

\section{Results and Discussion}

The initial step in analyzing the data was the calculation of the percentage of correct rankings by subjects. These percentages were then compared to what would be expected by chance. Using the binomial test, $z$ values were computed for the number of correct rankings of pairs of firms, triplets, and all four firms. The $z$ values were obtained by using the normal approximation to the binomial distribution. The calculations were done separately for each group of subjects receiving the different types of financial statements. The expectation and variance of the number of correct ranks $(R)$ were calculated as follows:

$$
\begin{aligned}
E(R) & =N P, \\
\operatorname{var}(R) & =N P Q,
\end{aligned}
$$

where

$N=$ total number of participants for each group;

$P=$ probability of ranking the firms correctly for pairwise triple and quadruple combinations, respectively, and

$Q=1-P$.

The central limit theorem was applied, which allowed the normal approximation and the transformation of the number of correct ranks $(R)$ into the standard normal deviates using the following formula: 


$$
z=\frac{R-E(R)}{\operatorname{var}(R)}
$$

Significant positive $z$ values indicate that subjects were able to rank the firms correctly at better than chance levels. Because larger $z$ values result from a greater percentage of correct rankings, the $z$ values can also be used as a measure of the degree of usefulness of the financial data under each of the alternative accounting methods.

A test for significant differences between the percent of correct rankings under CCC, TCC, and HC methods was also performed. This test utilized the $z$ values for a two-sided test.

Positive values for $z$ in this case indicate that a greater percentage of subjects correctly ranked the firms under the first method in each hypothesis as opposed to its competing method (TCC versus $\mathrm{HC}$ in $\mathrm{H1}, \mathrm{CCC}$ versus $\mathrm{HC}$ in $\mathrm{H} 2$, and $\mathrm{CCC}$ versus TCC in $\mathrm{H} 3$ ). Values for $z$ were again calculated for the percentage of subjects ranking pairs, triplets, and all four firms correctly.

Tables 2 and 3 summarize our findings. Table 1 presents the results of the test of actual correct rankings versus chance and indicates: (1) the number of participants under each alternative accounting method, (2) the number of correct ranks made by the participants in each category, (3) the related percentage of correct ranks, and (4) the $z$ values with the associated probability that the percentage of correct ranks for each accounting method was attributable to chance.

The results in Table 2 indicate that all three sets of financial data were useful in helping the participants rank order the firms. The subjects in this study made their decisions based solely on the financial information provided for the firms. They did not have access to any other economic information, and yet they generally ranked the firms correctly at a much better than chance level. ${ }^{6}$ More importantly, the subjects' performance differed by type of disclosure. A comparison of the $z$ values among the alternative accounting methods reveals that the $z$ values are greatest under $\mathrm{CCC}$, in the middle for TCC and are the smallest for HC. That is, there is an overall pattern of improvement in rankings from $\mathrm{HC}$ to TCC to CCC.

Table 3 presents the results of significance tests for differences between the percentage of correct rankings for $\mathrm{CCC}$ and $\mathrm{HC}, \mathrm{CCC}$ and TCC, and

6. If the statements were not useful, comparisons across types would be moot. Having additional nonaccounting data available would likely increase the percentage of correct rankings for all treatments and make the identification of differences across treatments more difficult to discover. One advantage of the instrument used is the ability to withhold such information thus improving the power of the experiment. 


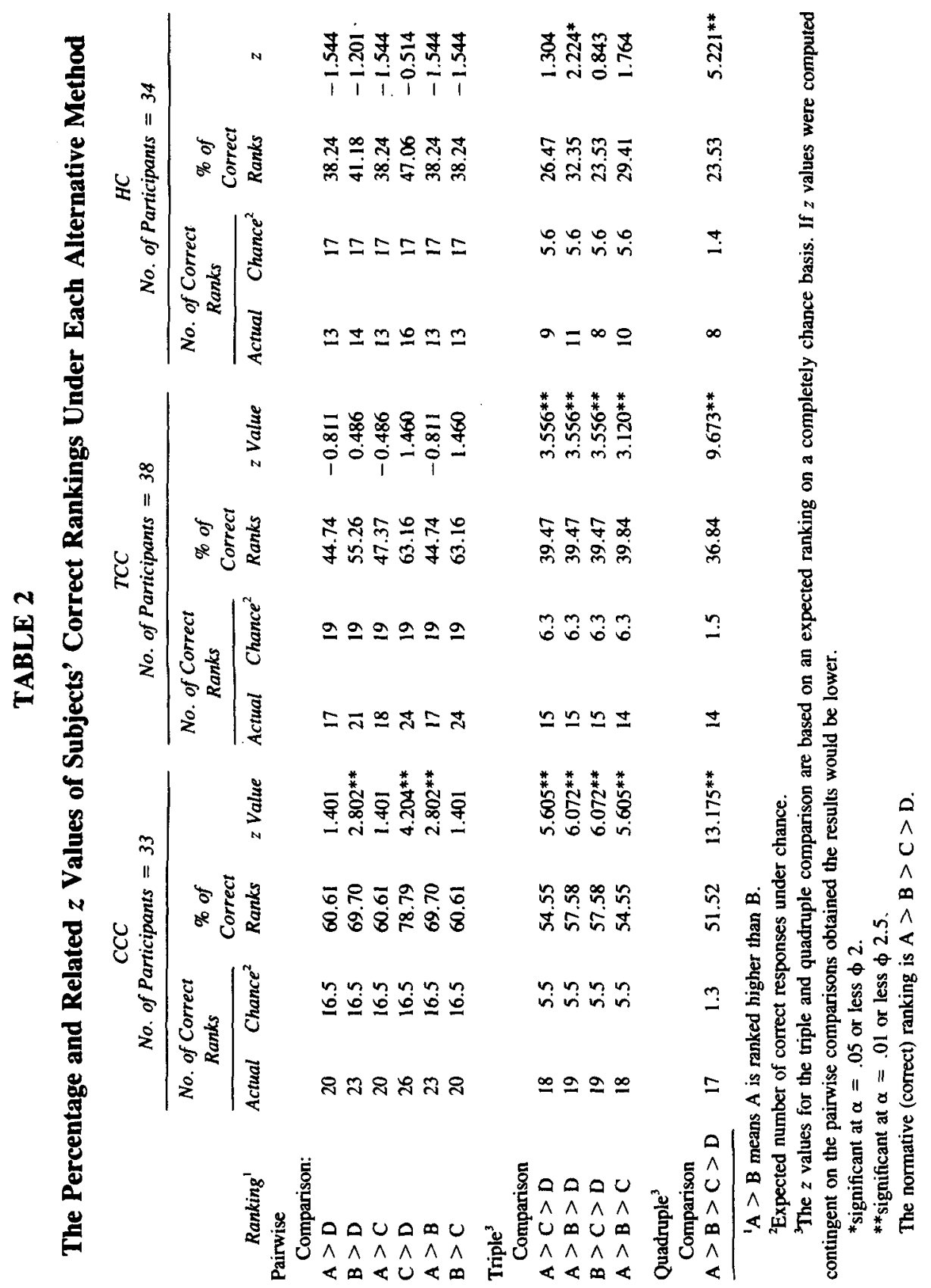




\section{TABLE 3}

\section{The Results of the Binomial Test for the Comparison of the Alternative Accounting Methods}

\begin{tabular}{|c|c|c|c|}
\hline Ranking & $\begin{array}{l}\text { Normal Deviate } \\
\text { (z) for } \\
\text { CCC versus HC }\end{array}$ & $\begin{array}{c}\text { Normal Deviate } \\
\text { (z) for } \\
\text { CCC versus TCC }\end{array}$ & $\begin{array}{l}\text { Normal Deviate } \\
\text { (z) for } \\
\text { TCC versus HC }\end{array}$ \\
\hline \multicolumn{4}{|c|}{ Pairwise Comparison: } \\
\hline$A>D$ & $1.831 *$ & 1.331 & 0.557 \\
\hline$B>D$ & $2.347^{*}$ & 1.246 & 1.190 \\
\hline$A>C$ & $1.831 *$ & 1.112 & 0.779 \\
\hline$C>D$ & $2.685^{* *}$ & 1.434 & 1.369 \\
\hline$A>B$ & $2.582 * *$ & $2.108^{*}$ & 0.558 \\
\hline $\mathrm{B}>\mathrm{C}$ & $1.831^{*}$ & -0.220 & $2.107^{*}$ \\
\hline \multicolumn{4}{|l|}{ Triple Comparison: } \\
\hline$A>C>D$ & $2.357^{* *}$ & 1.266 & 1.165 \\
\hline$A>B>D$ & $2.089^{*}$ & 1.518 & 0.626 \\
\hline $\mathrm{B}>\mathrm{C}>\mathrm{D}$ & $2.858 * *$ & 1.581 & 1.445 \\
\hline$A>B>C$ & $2.098^{*}$ & 1.491 & 0.666 \\
\hline \multicolumn{4}{|c|}{ Quadruple Comparison: } \\
\hline $\mathrm{A}>\mathrm{B}>\mathrm{C}>\mathrm{D}$ & $2.383 * *$ & 1.240 & 1.221 \\
\hline
\end{tabular}

TCC and HC. The results in Table 3 support $\mathrm{H} 2$, which hypothesized that current cost information improves decisions when the realized and unrealized components are separately disclosed. The difference between CCC and HC is significant at $\alpha<.05$ for all comparisons. As can be seen from Table 2 , the percentage of correct responses under $\mathrm{CCC}$ was 51 percent, compared to 37 percent for TCC and 23 percent for $\mathrm{HC}$.

$\mathrm{H} 1$ and $\mathrm{H} 3$ were not supported. The difference between $\mathrm{CCC}$ and TCC and between TCC and $\mathrm{HC}$ were in the predicted direction but were not significant at conventional levels. ${ }^{7}$ The observed $p$-value for TCC versus HC is .12 for the quadruple comparison, and for CCC versus TCC it is .11.

In summary, the results are consistent with the hypothesis that disclosure of current value income is useful for decisions when separated into trading (realized) and holding (unrealized) components. These results cast doubt on the suggestion by Ijiri and Noel [8] that historical cost statements are "better' than current cost statements. Although Ijiri and Noel also used a commodity trading firm for their analysis, they defined an income measure as

7. In addition to the results reported here we employed the Wilcoxin rank-sum test to examine which group of subjects was able to more accurately rank the firm. The results parallel those for the binomial test and are not reported here. 
"better" if it was more reliable using the Ijiri and Jaedicke [7] measure of reliability. We were able to circumvent their need for choosing a characteristic of a measure as reflecting a better measure of income. Instead, we measured the accuracy of user decisions. Hence, although we do not argue that the CCC income is better from the perspective of measured reliability, we do provide evidence of improved investment decisions using these data.

\section{Conclusions and Limitations}

The results of this study suggest that subjects performed better in ranking the attractiveness of commodities firms for investment when provided with current cost dichotomized data as opposed to only historical cost data. The study suffers from at least two limitations. First, by using firms dealing in commodity futures we exclude consideration of current values for fixed assets. Fixed assets are a significant asset for most firms. Second, because the subjects were not in an actual market setting, the subjects' decisions had no direct economic consequences. That is, subjects were not required to make investment decisions where actual payoffs depended on their decision. One extension of this research would be to conduct a laboratory market experiment in which the form of the disclosed information was the manipulated variable among markets. In this way, equilibrium implications of this disclosure issue could be examined.

In conclusion, prior studies have shown that financial statement users desire to have current cost information available, but there is little evidence that such data are actually useful. This study used a unique experimental approach in which it was possible to unambiguously identify the relative performance of firms. The instrument allowed us to evaluate performance in a realistic investment task, the ranking of firms, using three alternative forms of disclosure. Our results indicate that subjects performed better when given current cost data dichotomized between realized and unrealized holding gains and losses than when given only historical cost data. Thus, the results support the hypothesis that at least in some situations, current cost information is incrementally useful for decision making.

\section{REFERENCES}

1. Beaver, W. H., P. A. Griffin, and W. R. Landsman. 1982. "The Incremental Information Content of Replacement Cost Earnings." Journal of Accounting and Economics 4, no. 1 (July): 15-39.

2. Bublitz, B., T. Frecka, and J. McKeown. 1985. "Market Association Tests and FASB Statement No. 33 Disclosures: A Reexamination." Journal of Accounting Research 23 (Supplement): 1-23.

3. Casey, C. J., and M. J. Sandretto. 1981. "Internal Uses of Accounting for Inflation." Harvard Business Review 59, no. 6 (November/December): 149-156.

4. Estes, R. W. 1968. "An Assessment of the Usefulness of Current Cost and Price-Level Information by Financial Statement Users." Journal of Accounting Research 6, no. 2 (Autumn): 200-207. 
5. FASB Statement No. 33. 1979. Financial Reporting and Changing Prices. Stamford, Conn.: FASB, September.

6. Louis Harris and Associates, Inc. 1980. A Study of the Attitudes Toward An Assessment of the Financial Accounting Standards Board. Stamford, Conn.: Financial Accounting Foundation.

7. Ijiri, Y., and R. K. Jaedicke. 1966. "Reliability and Objectivity in Accounting Measurements." The Accounting Review 41, no. 3 (July): 474-483.

8. Ijiri, Y., and J. Noel. 1984. "A Reliability Comparison of the Measurement of Wealth, Income and Force." The Accounting Review 59, no. 1 (January): 52-63.

9. Matolcsy, Z. P. 1984. "Evidence on the Joint and Marginal Information Content of InflationAdjusted Accounting Income Numbers." Journal of Accounting Research 22, no. 2 (Autumn): $555-569$.

10. McDonald, B., and M. H. Morris. 1984. "The Relevance of SFAS 33 Inflation Accounting Disclosures in the Adjustment of Stock Prices to Inflation," The Accounting Review 59, no. 3 (July): 432-446.

11. McEnroe, J. E., and L. A. Nikolai. 1979. "How Useful is Inflation Accounting?" The CPA Journal 49 , no. 9 (September): 6-9.

12. Murdock, B. 1986. "The Information Content of FAS 33 Returns on Equity." The Accounting Review 61, no. 2 (April): 273-287.

13. Bildersee, John S., and J. Ronen. 1987. "Stock Returns and Real Activity in an Inflationary Environment: The Informational Impact of FASB No. 33." Contemporary Accounting Research 4, no. 1 (Fall): 80-110.

14. Schaefer, T. F. 1984. "The Information Content of Current Cost Income Relative to Dividends and Historical Cost Income." Journal of Accounting Research 22, no. 2 (Autumn): 647-656.

15. Securities and Exchange Commission. 1976. "Disclosure of Certain Replacement Cost Data." Accounting Series Release No. 190.

16. Sterling, R. R. 1970. Theory of the Measurement of Enterprise Income. Lawrence: The University Press of Kansas. 